\title{
«Juntas imparables». Género, clase y feminismo en las estrategias comerciales de Nike en Argentina*
}

\author{
Martín Álvarez Litke** \\ Nemesia Hijós***
}

* Una versión preliminar de este trabajo fue presentada como ponencia en las X Jornadas de Jóvenes Investigadores del Instituto de Investigaciones Gino Germani (Buenos Aires, Argentina) en noviembre de 2019. Agradecemos los comentarios y sugerencias de las y los colegas del Eje 4 «Tecnologías digitales y producciones estético culturales: consumos, política, cultura y comunicación».

** Profesor en Ciencias Antropológicas por la Facultad de Filosofía y Letras (FFyL) de la Universidad de Buenos Aires (UBA). Doctorando en Ciencias Antropológicas por la FFyL de la UBA. Correo electrónico: esnowel@hotmail.com

${ }^{* * *}$ Licenciada en Ciencias Antropológicas por la Facultad de Filosofía y Letras, y doctora en Ciencias Sociales por la Universidad de Buenos Aires (UBA). Magíster en Antropología Social por la Universidad Nacional de San Martín (UNSAM). Correo electrónico: nemesiahijos@gmail.com

Fecha de recepción: 01/04/20. Fecha de aceptación: 16/10/20. 
«Juntas imparables». Género, clase y feminismo en las estrategias comerciales de Nike en Argentina

\title{
RESUMEN
}

En el marco de la expansión de los feminismos, atendemos a la proliferación de publicidades que (re) producen miradas androcéntricas sobre los nuevos modos de ser mujer, alineados al imaginario de vida activa contemporánea que el mercado quiere enaltecer, exhibir, promocionar y propagar. Partimos de pensar las publicidades como «tecnologías de género» (De Lauretis, 1989) para analizar la estrategia comercial de la marca estadounidense Nike, líder en el mercado deportivo. En la actualidad, la empresa complementa sus publicidades televisivas con presencia en el terreno y en las redes sociales, buscando ampliar su red de impacto y llegar así a distintas consumidoras. En este artículo nos preguntamos cómo Nike busca interpelar a las mujeres en múltiples escenarios y qué consecuencias tienen las prácticas de la marca sobre la subjetividad y la materialidad de las deportistas. Para ello, reflexionamos a partir de nuestros registros de observación de trabajo de campo sobre running y fútbol practicado por mujeres en distintos contextos en la ciudad de Buenos Aires (Argentina) y analizamos una serie de publicidades, videos y publicaciones en redes sociales, donde las actividades deportivas son representadas como modelo o ejemplo del nuevo ideal de individua y de cuerpo femenino.

Palabras clave: mujeres, feminismos, consumos, marcas deportivas, publicidades.

\section{«Unstoppable Together». Gender, Class and Feminism in Nike’s commercial stra- tegies in Argentina}

\begin{abstract}
In the framework of the expansion of feminisms, we attend to the proliferation of advertisements that (re)produce androcentric views on the new ways of being woman, aligned to the imaginary of contemporary active life that the market wants to exalt, display, promote and propagate. We start by thinking of advertising as "gender technologies" (De Lauretis, 1989) to analyze the commercial strategy of the American brand Nike, leader in the sports market. Currently, the company complements its advertisements with a presence in the field and on social networks, seeking to expand its impact network and thus reach different consumers. In this article we question the ways in which Nike seeks to engage women in multiple scenarios, and investigate the consequences that the brand's practices have on the subjectivity and materiality of athletes. To do this, we reflect on our ethnographic records on running and football practiced by women in different contexts in the city of Buenos Aires (Argentina), and analyze a series of advertisements, videos and images on social media, where sports activities are represented as a model or example of the new individual and female body ideal.
\end{abstract}

Keywords: women, feminisms, consumptions, sport brands, advertisements. 


\section{INTRODUCCIÓN}

¿Qué es lo que quieren las mujeres? La pregunta sobrevuela mientras vemos en la pantalla a una mujer corriendo, sola, atravesando un camino de asfalto en la montaña. De fondo, una voz en off' relata:

Nadie se queda delante del espejo antes de salir a correr, la calle no va a pensar sobre tu vestimenta. No tenés que escuchar sus bromas y pretender que son graciosas. No sería más fácil si te vestís sexy. Nadie notaría si no estás usando lápiz labial. No te sentirías incómoda si ganás más dinero que la calle. Y podés llamar a la calle cuando ha sido un mal día, al menos un par de horas. De la única cosa que se preocupa la calle es que la visites. Nike. Nada de juegos, simplemente deportes (Lo que ellas quieren, 2000).

Pasaron veinte años del estreno de la película estadounidense Lo que ellas quieren, protagonizada por Mel Gibson y Helen Hunt, en la que el personaje principal, un hombre adulto, de clase media y profesional, con actitudes claramente machistas, adquiere la habilidad de escuchar los pensamientos de las mujeres y de repente su vida cambia. A partir de esta cualidad, el protagonista diseña una estrategia para venderle a Nike - la empresa deportiva más importante del mundo- una nueva campaña publicitaria para su línea Nike Women. El personaje del film proponía a las ejecutivas de la marca ${ }^{2}$ el lema encuentra el tiempo, como una frase para motivar a las mujeres a que ocupen el espacio público — la calle—, no solo para ejercitarse y tener un tiempo para ellas, sino como una postura de autonomía, determinación y empoderamiento frente a la organización de la sociedad y de la vida.

La mística de poder captar aquello que las mujeres quieren, estar a tono con las dinámicas, discusiones y luchas sociales subyace en las publicidades de Nike de las últimas décadas, pero esto no siempre fue así. Durante la década de 1980, la marca disputaba por el primer lugar en la industria del calzado deportivo con Reebok, que había enfocado su estrategia de marketing en el ejercicio de aerobics para las mujeres. Hacia el final de esa década, las lógicas del mercado empujaron a que Nike persiguiera el liderazgo en la comercialización de indumentaria deportiva femenina (Lucas, 2000, pp. 150-151). Según Shelley Lucas (2000), el Título IX de la Ley de Enmiendas de Educación de 1972 de Estados Unidos fue el antecedente clave para el eventual reconocimiento y desarrollo del mercado del deporte y del fitness dirigido a mujeres. Esta disposición, que establece que ninguna persona puede ser

\footnotetext{
1 La cursiva en el cuerpo del texto debe entenderse como una apropiación del discurso de nuestros interlocutores y para resaltar palabras en otro idioma.

2 Cabe mencionar que las mujeres que escuchaban la presentación del protagonista en la película efectivamente trabajaban para Nike, no eran actrices, lo que da cuenta de la participación activa de la empresa en el film.
} 
excluida de una actividad educativa por razones de sexo, es un logro de la lucha feminista estadounidense, cuyas militantes se preocuparon por la desigualdad de género en el deporte mucho antes de lo que ocurrió en el feminismo argentino. Esta ley impulsó un aumento sin precedentes de mujeres y niñas que empezaron a participar de la vida atlética, lo que se tradujo en un aumento del consumo de indumentaria deportiva para este sector. Así, las mujeres compraron más calzado deportivo que los varones - por primera vez en la historia - en 1994, y en 1995 lideraron las participaciones en actividades fitness (Lucas, 2000, p. 151). Fue en este contexto cuando Nike dio un giro en la planificación de sus spots comerciales, apuntando a la participación de las mujeres en actividades deportivas anteriormente reservadas solo a los varones.

En la actualidad, Nike complementa sus publicidades televisivas con una presencia activa en redes sociales y en el territorio, organizando y respaldando iniciativas vinculadas con las prácticas deportivas. El propósito de la empresa es ampliar su red de impacto y llegar a distintas consumidoras. Precisamente, durante nuestras investigaciones etnográficas sobre actividades físicas realizadas por mujeres en Buenos Aires (Argentina), identificamos la presencia de la marca en contextos tan variados y disímiles como el acaudalado barrio de Palermo y la Villa 31, el asentamiento de emergencia más grande de la ciudad. Esto nos lleva a examinar cuáles son los efectos de la omnipresencia de la marca en el deporte argentino y a analizar la interrelación entre sus múltiples estrategias — las campañas publicitarias, el marketing experiencial y los proyectos de impacto comunitario - en un escenario en el cual las reivindicaciones feministas cobran una relevancia inédita en el país. Para ello nos preguntamos: ¿Cómo se configuran el género y el cuerpo desde la empresa de calzado e indumentaria deportiva más importante? ¿Cómo busca Nike interpelar a las mujeres en los distintos contextos socioeconómicos en los que opera? ¿Qué mujeres «feministas» son representadas en las campañas publicitarias?

\section{Metodología}

Para esbozar una respuesta a estos interrogantes apelaremos a la utilización la etnografía, ya que a través de sus técnicas se logra acceder a las prácticas de los actores sociales y los significados que estas tienen para ellos. Las observaciones etnográficas en sus contextos de entrenamiento - el hecho de poner el cuerpo- nos permiten comprender lo que sienten, viven y piensan las personas, responder qué relaciones se construyen entre deporte, cuerpo, género, moralidades y consumo, ahondar en sus representaciones y en los valores que se ponen en juego en la práctica deportiva. Para comprender estas experiencias desde las lógicas de los actores, retomamos la propuesta de Rosana Guber (2001) de concebir la etnografía como un enfoque, un 
método y un texto, porque con este instrumento podremos entender los significados, las prácticas y los imaginarios significativos para nuestros interlocutores. Esta decisión metodológica nos permite ver de primera mano la actuación de Nike en los distintos territorios y los modos en los cuales se relaciona con sus consumidores. Las experiencias etnográficas analizadas en el presente artículo surgen de nuestras investigaciones individuales en torno al running y al fútbol practicados por mujeres en Buenos Aires, en las cuales tenemos la posibilidad de observar lo que Nike hace y dice que hace. No obstante, si pretendemos estudiar las representaciones de género y feminismo de la empresa, no basta con detenernos en su actuación en el terreno, sino que también es necesario analizar los mensajes que transmite a través de sus publicidades. Para ello, seleccionamos un corpus de comerciales a partir de la centralidad que tuvieron estos spots en los debates de los colectivos feministas y de su repercusión en los medios de comunicación en Argentina ${ }^{3}$.

\section{GÉNERO, CLASE Y FEMINISMO EN NiKE}

El deporte emerge como un campo rico para observar y analizar procesos fundamentales en la constitución de la desigualdad social, y permite fusionar experiencias que en general se consideran contrapuestas: el ocio y el trabajo, el individualismo y el colectivismo, lo lúdico y lo serio, la jerarquía y la igualdad. Pocos aspectos de la vida cotidiana ponen en primer plano la clase social y el género de una manera más evidente que el deporte, precisamente porque el funcionamiento de las jerarquías en el conjunto de la sociedad queda expuesto en estas prácticas.

La práctica deportiva nos permite ver ciertas disposiciones y cuerpos en movimiento: cómo nos movemos, nos paramos, nos vestimos, cómo interactuamos con otros en los contextos que nos rodean. Las elecciones de actividades deportivas que hacen las personas ya sea como practicantes o espectadores, están en gran medida configuradas por sus posiciones de clase y esto quiere decir también por los accesos que de esa posición se desprenden (Bourdieu, 1990). Así, el deporte tiende a amplificar las diferencias de clase al incluir a algunos grupos y excluir a otros. De esta forma, las distinciones en el consumo y la estética, se traducen en desigualdades. Al mismo tiempo, los deportes se han configurado históricamente como divididos por género, designando símbolos, comportamientos, roles y estatus, fijando categorías de lo femenino y lo masculino (Scharagrodsky, 2016).

\footnotetext{
3 Podemos ver cómo estos distintos análisis ocuparon relevancia en los principales medios de Argentina: https://bit.ly/2N6IiKf (Clarin, 1 de septiembre de 2018); https://bit.ly/37FulMP (Infobae, 1 de septiembre de 2018), y en los portales de referencia: https://bit.ly/2UQUmDO (Economía Feminista, 1 de septiembre de 2018) y https://bit.ly/2V9XWJp (Feminacida, 2 de septiembre de 2018).
} 
El running no queda exento de todas estas disposiciones: está atravesado por la lógica del mercado, que ha reconfigurado la práctica como una industria y por ende presupone una inversión económica significativa. Por ende, para pertenecer a este grupo social y no ser un outsider, quienes vivencian esta actividad como parte de su identidad demostrarán esta pertenencia a través de ciertas prácticas y consumos: pagar la inscripción a una carrera, comprar los productos considerados fundamentales para su práctica (zapatillas, indumentaria, accesorios, relojes, viajes) (Gil, 2018). Estos también son indicadores de exclusividad, distinción y ostentación, y todo este despliegue que tiene valor entre sus practicantes requiere de inversión económica (Bourdieu, 2012). Durante nuestros trabajos de campo advertimos el lugar de visibilidad y reconocimiento que ocupa Nike dentro de este mercado, por la supuesta calidad de su indumentaria y calzado, pero también por el prestigio, estatus y distinción asociado a la exclusividad y al costo de sus productos.

$\mathrm{Si}$ como dijimos, ciertos deportes son asociados a determinadas clases sociales y géneros, estas asociaciones son construcciones culturales que tienen una historia y que no se dan de una vez y para siempre (Bourdieu, 1990). Estas valoraciones se modifican con el tiempo y de acuerdo al contexto en el cual se encuentran insertas, y una empresa como Nike resulta un actor fundamental en estos cambios, en tanto comercializa productos para una amplia gama de deportes y actividades físicas. En el caso del fútbol, por ejemplo, que históricamente ha estado asociado al dominio masculino y a los sectores populares, la intervención de las marcas ha actuado como un motor para atraer nuevas consumidoras y transformarlo en un nicho transclasista. El incipiente mercado ha contribuido a suprimir y combatir la imagen de jugadoras "machonas», "negras» o "villeras», desarrollando estrategias de marketing y publicidad que posicionan y legitiman la disciplina. Este enfoque propone el fútbol como espacio social y recreativo aceptable para mujeres donde no hace falta perder la femineidad (Garton e Hijós, 2018). Nike participa de esta (re)definición de los significados de los deportes en términos de clase y de género, adaptándose al escenario de luchas y demandas sociales, ajustando las formas en que interpela a sus posibles consumidoras. A través de la publicidad, el rol de marcas como Nike es fundamental para moldear imaginarios.

En este sentido, numerosos investigadores (Calvo Ortega, 2014; Cranmer y otros, 2014; Cooky y otros, 2015; Reichart Smith y Sanderson, 2015) han identificado a las publicidades como dispositivos a través de los cuales se refuerzan los estereotipos de género, mostrando a mujeres y niñas en roles pasivos, promocionando para ellas productos de belleza y juguetes asociados a tareas de cuidado y el hogar, mientras que para los varones se promueven deportes, y son representados con características ligadas a la masculinidad: fuerza, agresividad, resistencia. Siguiendo a Teresa De Lauretis (1989), sostenemos que se trata de auténticas «tecnologías de género», que producen el género a través de su representación. 
Como mencionamos anteriormente, hacia fines de la década de 1980 y durante la de 1990 Nike modificó sus estrategias comerciales para apuntar a un público femenino en franco crecimiento. Sus publicidades sugerían la posibilidad de que mujeres y nińas se empoderaran a través del deporte, pero al mismo tiempo reforzaban ideologías dominantes que normalizaban que las mujeres debían pedir permiso (Lucas, 2000). La marca se representaba a sí misma como la herramienta facilitadora del acceso a la práctica del deporte para las mujeres, quienes eran representadas como carentes de agencia propia, negando su autonomía respecto a las decisiones sobre sus cuerpos. En estas imágenes publicitarias las mujeres se muestran en movimiento y activas, con una elevada autoestima y bienestar, alineadas al imaginario de vida activa contemporánea y los valores de la eficiencia y productividad que el mercado quiere enaltecer, exhibir, promocionar y propagar. Sin embargo, los comerciales no dejan de reproducir miradas androcéntricas donde el cuerpo aparece como un objeto deseable: un cuerpo integralmente tonificado, estilizado, armónico y delgado. A través de las publicidades, se busca presentar una unificación no contradictoria de imágenes de feminismo y femineidad, dando lugar a un "feminismo estéticamente despolitizado» (Goldman, Heath y Smith, 1991, p. 334): la empresa se apropia de la potencia cultural y la legitimidad social de este movimiento contestatario al mismo tiempo que contiene y domestica sus críticas al sexismo y la desigualdad estructural.

En la misma dirección apuntan las incursiones de Nike vinculadas al deporte para el cambio social y al trabajo en territorio. En un contexto de auge neoliberal y feminización de la pobreza, en el cual las mujeres del sur global han sido apuntadas como destinatarias de iniciativas en pos del desarrollo, Ginger Boyd (2016) destaca que existe una tendencia de grandes empresas a invertir en educación para niñas y adolescentes tercermundistas a través de programas de responsabilidad social corporativa y alianzas entre el sector privado y el público (p. 147). Esta tendencia ha sido identificada como el Girl Effect, tomando el nombre de la campaña de responsabilidad social corporativa lanzada por Nike en el año 2008 en asociación con la Organización de las Naciones Unidas y la Organización Mundial de la Salud (Banet-Weiser, 2015, p. 60).

Durante la última década, Nike ha lanzado una serie de campañas que se inscriben en este paradigma, con el propósito explícito de empoderar a millones de nińas y adolescentes que viven en la pobreza, y el objetivo implícito de limpiar su imagen tras las denuncias respecto de la explotación de mujeres y menores de edad para la fabricación de sus prendas (Boyd, 2016, p. 151). De acuerdo con Sarah Banet-Weiser (2015), las niñas son vistas como un grupo vulnerable, en crisis, y al mismo tiempo como un nicho de consumidoras increíblemente lucrativo (p. 60). Se impulsa a estas nińas para que se conviertan en emprendedoras, entendiendo a las mujeres pobres como las 
sujetas neoliberales por excelencia, pues se asume que para sobrevivir han tenido que desarrollar las capacidades proactivas buscadas por las grandes marcas (Koffman y Gill, 2013 en Banet-Weiser, 2015). El empoderamiento entendido en estos términos responde a los objetivos de un feminismo liberal que se enfoca en la superación individual pero no cuestiona las estructuras de desigualdad, disfrazando la explotación tras la fachada de un discurso «feminista» (Banet-Weiser, 2015; Boyd, 2016).

A continuación, analizaremos de qué manera se manifiestan los procesos de representación del género y la apropiación de discursos feministas en una serie de campañas publicitarias y estrategias en el terreno llevadas adelante por Nike en la ciudad de Buenos Aires, atendiendo a las múltiples maneras en que esta empresa interpela a sus consumidoras en contextos sociales diversos.

\section{LAS CAMPAÑAS «FEMINISTAS» DE NIKE}

La campaña Dream crazier ${ }^{4}$ lanzada por Nike en febrero de 2019 se planteó como una vía para luchar contra la discriminación de género en el deporte. La publicidad retoma una serie de estereotipos respecto de las mujeres deportistas: dramáticas, delirantes, desquiciadas, irracionales, histéricas, locas; mientras se muestran imágenes de mujeres corriendo una maratón, boxeando, haciendo una volcada, entrenando a un equipo de la NBA, compitiendo en hiyab o jugando al tenis. En la voz de la atleta multicampeona Serena Williams, una de las frases finales de la publicidad propone: "Así que, si quieren llamarte "loca”, está bien. Muéstrales lo que las locas pueden hacer». El mensaje es subvertir el estigma de la locura y convertirlo en motivación para las próximas generaciones, impulsando el espíritu de la (auto) superación, de romper barreras y sobreponerse a los prejuicios.

En el marco local, esta publicidad tuvo su correlato en el spot audiovisual Antes que nada , lanzado en mayo de 2019, que tenía como protagonista central al fútbol

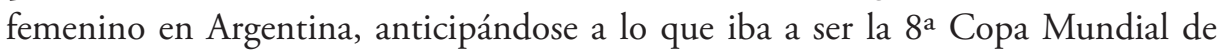
Fútbol organizada por la Fédération Internationale de Football Association (FIFA) a disputarse en junio y julio de ese año en Francia. Las protagonistas son Estefanía Banini, Ruth Bravo y Belén Potassa (tres jugadoras de la Selección Nacional de Argentina), además de Candelaria Cabrera, una niña de ocho años a quien su club le impedía jugar al fútbol con varones y se convirtió en un símbolo de la lucha por igualdad de género en este deporte ${ }^{6}$. En la voz de Candelaria, la publicidad anuncia:

\footnotetext{
Ver en: https://bit.ly/2AgKpbu

Ver en: https://bit.ly/2rDWGSY

6 Finalmente, tras la repercusión mediática, el alcance internacional y la difusión del conflicto con las autoridades de Huracán de Chabás (Santa Fe), los responsables del club deportivo le permitieron jugar en la institución y se comprometieron a crear una liga de mujeres.
} 
Para cumplir el sueño de salir campeona, primero tenés que ganar la final. Y para ganar la final, antes tenés que ser imparable. Pero antes tenés que trabajar duro, aunque este trabajo no pague las cuentas. Y mucho antes tenés que convertir las críticas en combustible. Y antes tenés que poner a prueba tu fortaleza. $\mathrm{Y}$ antes de eso hay que jugar en canchas imposibles o en canchas en las que ninguna mujer jugó antes [...].

El cierre del spot crea lazos con la campaña Dream crazier, haciendo referencia al estereotipo de la locura. Mientras en la imagen se observa a Candelaria acomodando la pelota para patear un penal, la cámara la enfoca de perfil dando la sensación de que está sola, y ella pronuncia la frase: "pero antes que nada te van a decir que una nena jugando al fútbol es una locura». En ese momento, mientras Candelaria toma carrera, la cámara gira y la muestra de frente, revelando que detrás de ella hay un enorme grupo de mujeres futbolistas (vestidas con indumentaria de la marca). «Demostremos lo que esa locura puede lograr», concluye Candelaria, mientras la cámara se acerca a la primera fila de la multitud en la que se reconoce a futbolistas como Camila Gómez Ares, Florencia Quiñones y Eliana Stabile (jugadoras del club Boca Juniors). La imagen pasa a un plano cenital en el cual vemos al grupo correr junto a Candelaria, seguida por una placa negra con letras blancas que deletrean la frase «Parece una locura hasta que lo hacés», que finalmente es reemplazada por Just do it y la famosa pipa de Nike.

El spot publicitario nos transmite, por un lado, la apelación al esfuerzo individual, a los sacrificios que una futbolista tiene que hacer para cumplir lo que desea y alcanzar sus sueños. Pero por otro lado esas representaciones de mujeres individuales se complementan con imágenes de celebración en equipo y festejos colectivos. El mensaje del final es que aquella niña que solo quería jugar y no la dejaban (ya) no está sola, porque las luchas de una mujer por la igualdad son sostenidas por otras mujeres.

Esta referencia a las mujeres como colectivo ya estaba presente en el comercial Juntas imparables ${ }^{7}$ (2018), antecedente de esta campańa. La publicidad fue grabada en México, pero tuvo repercusión y circulación en toda América Latina, en especial en contextos de militancia social, colectivos feministas y espacios de discusión académica por las supuestas referencias a la Campaña Nacional por el Derecho al Aborto Legal, Seguro y Gratuito en Argentina. Estas presunciones se atribuían al color verde del cuello del vestido de la protagonista de Juntas imparables, similar al pañuelo que simboliza la lucha por la legalización del aborto. Con alusiones generales a distintos deportes, este comercial comienza con un embotellamiento en las calles de la Ciudad de México: una madre le aplica fijador en el cabello enrulado a su hija, diciéndole:

\footnotetext{
Ver en: https://bit.ly/2RGVVDs
} 
«pero es que se te ve más bonito». La joven se fastidia, sale a través de la ventana y se sienta en el techo del auto. Allí ve a una mujer que avanza corriendo mientras los vehículos se mantienen estáticos. La cámara enfoca el calzado rosa de la protagonista mientras se ata los cordones, y al grito de ¡vámonos!, sale corriendo junto con otras dos jóvenes, persiguiendo a la runner. Lo que se observa en esta escena es un juego entre imágenes de inmovilidad y de movimiento, donde las primeras tienen una carga negativa (asociadas a los estereotipos de belleza tradicionales que constriñen a la mujer), y las segundas aparecen como lo deseable, con el objetivo de fomentar la cultura física y deportiva. La forma de superar la incomodidad, la desesperación y el mal humor del tráfico es calzarse las zapatillas y empezar a correr.

La publicidad continúa: la protagonista salta para esquivar un obstáculo, su vestido se levanta mostrando sus piernas, y un hombre corpulento que come un hot dog le silba, pero es increpado por un autobús repleto de mujeres, una de las cuales le lanza una pelota de básquet que lo golpea y le hace soltar el hot dog. Se van sumando mujeres que corren, hacen acrobacias y juegan al fútbol, hasta que finalmente llegan a una obra en construcción donde obreros y policías se ríen condescendientemente de ellas y les dicen: «métanse a sus carros». El avance de las mujeres parece detenerse un segundo, hasta que se abre paso una boxeadora que golpea unas bolsas de cal. Estas estallan en una nube de polvo, de cual emerge la joven protagonista montando un caballo blanco con el puño en alto, liderando a las demás mujeres. En esta escena, la protagonista lleva puesto el vestido aguamarina tapando su boca y su nariz como si fuera un pańuelo. La asociación con el pańuelo verde que simboliza la lucha por el aborto en la Argentina —extendida a otras partes de América Latina — no parece casual. La publicidad termina con esa imagen y la frase Juntas imparables, seguida de Just do it, junto con una pantalla negra con la pipa blanca de Nike. El mensaje que transmiten estas secuencias es que las mujeres unidas y en movimiento pueden sobreponerse a las actitudes machistas encarnadas por las figuras masculinas en la publicidad.

Como planteamos anteriormente, al entender a las publicidades como tecnologías que producen el género a través del mismo acto de su representación, nos preguntamos por las implicancias de estas campañas para los imaginarios sociales: ¿Qué ocurre cuando una empresa como Nike atiende a los reclamos feministas y subvierte los estereotipos de género? ¿Qué efectos genera la representación de mujeres en roles activos, practicando deportes históricamente vedados para ellas? El hecho de que aparezcan nuevas imágenes de mujeres en las publicidades es un evidente avance en el sentido de ampliar los modelos y las referencias, especialmente para las niñas y jóvenes. Estas campañas rompen con determinados estereotipos, pero ¿qué representaciones están produciendo? Como plantea De Lauretis (1989): «si la desconstrucción de género inevitablemente produce su (re)construcción, 
la pregunta es ¿̇en qué términos y en interés de quiénes es producida la de-re-construcción?» (p. 32).

En este sentido, lejos de celebrar acríticamente este viraje en la representación de feminidades en la publicidad, es necesario indagar respecto de las consecuencias imprevistas de estas publicidades: ¿Qué nuevas imágenes de las mujeres se cristalizan? ¿A quiénes exaltan y a quiénes excluyen? Por un lado, en la elección de las protagonistas de estas campańas se mantienen criterios estéticos que responden a una belleza hegemónica y revelan un cuerpo fit: musculoso pero no demasiado, fuerte pero a la vez esbelto (Garton e Hijós, 2017), excluyendo otras corporalidades posibles. Por otro lado, estas representaciones de mujeres deportistas todavía mantienen un modelo binario heteronormativo y no presentan márgenes para la visibilidad de otras identidades sexo-genéricas. A su vez, debemos advertir que el mensaje de empoderamiento y liberación femenina que buscan promover las publicidades de Nike, se contradice con la explotación de mujeres y niñas reales, empobrecidas y racializadas, en la fabricación de estos productos promocionados a través de campañas «feministas». Por último, nos preguntamos si existe una continuidad entre las imágenes que divulga Nike en sus comerciales y las estrategias que la marca lleva adelante con las deportistas en el terreno. Para reflexionar sobre este punto nos adentraremos en nuestras experiencias en el campo ${ }^{8}$.

\section{ESTRATEGIAS EN EL TERRENO}

\subsection{El marketing experiencial en Nike+ Run Club Buenos Aires}

Nike+ Run Club (NRC) es un running team no arancelado auspiciado por Nike en Buenos Aires al igual que en otras cuarenta ciudades del mundo. Fue creado en 2014 en Estados Unidos como una apuesta del marketing experiencial para tener mayor impacto y liderar el mercado del running. Desde hace algunos años, este tipo de marketing se ha vuelto habitual en los espacios de venta como una herramienta innovadora para que los clientes perciban, sientan, piensen y actúen los valores que busca transmitir la empresa, y se relacionen consecuentemente con ella (Schmitt, 1999). Con el propósito de mantenerse como una marca novedosa y a la vanguardia, a través de este grupo de running, Nike invita a vivir experiencias, utilizando sus productos de forma motivacional, involucrándose con los participantes para seguir expandiéndose como companía líder en el mercado. Así, la propuesta incluye entrenamientos no arancelados organizados en sesiones, eventos especiales

\footnotetext{
8 Las dos experiencias etnográficas surgen de nuestras propias investigaciones individuales. Por lo tanto, si bien el artículo fue escrito en conjunto utilizando la primera persona del plural, en los casos específicos de cada campo la reflexión está presentada en primera persona del singular.
} 
y celebraciones, buscando interpelar a (futuros) consumidores, invitándolos a practicar deportes mediante una modalidad divertida, festiva, entre amigos, pero con un «entrenamiento exigente y de calidad», definido así por Tincho, uno de los dos coaches (instructores) de NRC Buenos Aires.

Si bien NRC se presentó como un espacio abierto, para todos y de disfrute, durante el tiempo que funcionó en Argentina (desde octubre de 2015 hasta mediados de 2018), la empresa fijó como punto de encuentro el vistoso local Nike Store del shopping Alto Palermo ${ }^{9}$, buscando integrar el espacio físico de un comercio de indumentaria deportiva con las herramientas digitales y el servicio de clases de running y entrenamiento, con una clara visión del público sectorizado - de clase media y alta - al que estaba apuntando. En una reunión que tuve con Vera Ferreira, ${ }^{10}$ Directora de Marca de América Latina para Nike, hizo mención a que este shopping era considerado un centro de compras para mujeres. Como el sector femenino es el que más consume, la marca decidió estratégicamente organizar sus salidas grupales de running desde este punto, acaparando así más atención y visibilidad.

Quienes asisten a las sesiones y a los eventos especiales organizados por NRC visitan con frecuencia el Nike Store del Alto Palermo, para confirmar la inscripción iniciada desde la aplicación digital y desde dicho punto de encuentro iniciar las actividades. Entre el público que concurre encontramos heterogénea cantidad de mujeres y varones entre 25 y 45 años aproximadamente, que en su mayoría buscando nuevos vínculos de sociabilidad a partir del deporte, aunque también hay casos de personas mayores con amplia trayectoria y participación en carreras, y menores que se suman entusiasmados por la posibilidad de estar en contacto con el mundo de las celebridades asociadas a la marca.

Cuando se inauguró el local del shopping Alto Palermo, la marca lanzó el Nike Women Victory Tour («Tour de la victoria de las mujeres») para seguir extendiendo el running globalmente y apuntando al sector femenino, mediante una serie de medias maratones exclusivas para mujeres organizadas de marzo a septiembre de 2016 en varias ciudades. La página web oficial ${ }^{11}$ indica que el objetivo es «inspirar y motivar a atletas en la serie de eventos más grande para el sector femenino, para que superen sus límites y alcancen sus metas, conectándose y formando parte de la comunidad Nike+». Se anunciaba como motor de estos encuentros el empoderamiento feme-

9 Con $1400 \mathrm{~m}^{2}$, este Nike Store es el más grande de América del Sur. Se encuentra en el Alto Palermo, un moderno centro comercial ubicado en el acaudalado barrio de Palermo de la ciudad de Buenos Aires. Según un empleado de la compañía que organiza los eventos para Nike, el local facturó entre \$100 000 y $\$ 170000$ por día en el período 2015-2016 (entrevista con Dionisio, 6 de octubre de 2017).

10 Con excepción de las personas públicamente conocidas, los nombres de nuestras interlocutoras en el trabajo de campo fueron modificados para resguardar su anonimato.

11 Ver más en la página de Nike: https://swoo.sh/2PfTdmI 
nino a través del deporte, "para derribar prejuicios sobre la fuerza y la resistencia, y demostrar a las mujeres que también podemos correr [esta distancia] si nos lo proponemos». El spot del Victory Tour ${ }^{12}$ estuvo acompañado con gráfica alusiva a las alas de la diosa griega de la victoria Niké, referente inspiradora de la marca. El lema de la carrera, Join the journey and show the world your wings ("Únete al viaje y muéstrale al mundo tus alas»), presenta una metáfora entre las alas y la liberación femenina, y al proponer que «rompan barreras», realza el repertorio de autosuperación constante, presente en el campo deportivo en un contexto donde el ejercicio actúa como una de las marcas de diferenciación más efectivas.

Esta campaña no tuvo publicidades «tradicionales»; Nike utilizó la plataforma NRC para hacer extensiva la promoción a las mujeres en cada país en el cual se programó la carrera. Al igual que en otras ciudades icónicas del mundo, la estrategia publicitaria en Buenos Aires fue motorizada a través de coaches y pacers en las sesiones de entrenamiento, así como también por personalidades ligadas a la marca en eventos especiales organizados por la empresa, donde se otorgan productos de la marca en carácter de regalos a quienes participan. Antes de la fecha de la carrera de 21 kilómetros para mujeres, jóvenes atletas asociadas a Nike divulgaron —mediante publicaciones en redes sociales - distintas sesiones de running llamadas «Vení a correr con nosotras». Esta es una forma de promocionarse que ha adoptado la compañía en épocas recientes: a través de embajadores e influencers, busca asociarse con una imagen de prestigio y vida atractiva, de contribuir al bien común sea este cultural, humanitario o ecológico, es decir, una forma de experimentar bienestar y acercamiento al mandato social de felicidad (Arizaga, 2017; Ahmed, 2019). Nike extendía la invitación a todas aquellas mujeres que quisieran divertirse corriendo, para animarse a más, buscando una mejor versión de sí mismas, para que se sientan identificadas hacia sus consumos y modos de vida, para atraer y consolidar consumidoras fieles, a la vez que ellas mismas sean medios de divulgación y promoción.

Durante estas sesiones, los coaches pautan las instrucciones generales, mientras que los y las pacers están encargados de guiar un ritmo determinado durante la actividad física, se trate de carreras de media o larga distancia, o pasadas de velocidad. Estos corredores experimentados funcionan como guías, a quienes se puede seguir sabiendo que se llegará a la meta en el tiempo planificado. NRC Buenos Aires cuenta con treinta pacers, equitativamente repartidos entre mujeres y varones jóvenes, que van rotando en las distintas sesiones semanales. Las pacers son jóvenes, de tez blanca, atléticas, con cuerpos socialmente deseables que responden a los estereotipos hegemónicos de belleza femenina. En una entrevista con Dionisio - encargado de la organización de eventos de Nike en Buenos Aires— reconoció que en los procesos de

\footnotetext{
12 Ver en: https://bit.ly/358PTPY
} 
selección de pacers, participantes, deportistas y personalidades asociadas a la marca hay un foco en la feminidad y en los cuerpos «fit», musculosos pero no demasiado, fuertes aunque a la vez esbeltos.

La gran mayoría de las pacers tiene el pelo largo y lacio, lo llevan recogido con la icónica colita de la mujer deportista; algunas van maquilladas de forma delicada con base, máscara alargadora de pestańas, ojos delineados suavemente en negro y algún brillo labial. Rara vez se las ve transpirar, por sus movimientos y estética parecen modelos, atrapan la mirada de mujeres y varones que asisten a NRC, y - tanto a partir de sus intervenciones en los entrenamientos como en sus publicaciones en las redes sociales - se vuelven referentes en aspectos estéticos y morales sobre cómo se practicar el running y vivir una vida activa. Los instructores varones también responden al estereotipo ideal de belleza, sus cuerpos son fuertes, atléticos y trabajados, y mantienen un cuidado de su imagen: la barba recortada de forma fina y prolija, el cabello peinado con gel, y cortes a la moda. Esta disposición refuerza la posición histórica y culturalmente aceptable de que los cuerpos que practican deportes «adecuados para su género" son atractivos y resultan un objeto de deseo. Toma fuerza entonces la idea de que NRC, además de ser un lugar que impulsa el entrenamiento de forma divertida y da apertura a la sociabilidad, es también un espacio de construcción generizada de subjetividades vinculadas a la belleza de los cuerpos.

En mi caso particular, mientras realizaba trabajo de campo en NRC, recibí productos en carácter de regalos por parte de la empresa, fui invitada a participar de eventos especiales, incluso a reunirme con Vera para conversar sobre mi investigación. En estos intercambios me propuso sumarme a la marca como influenciadora, lo que significaba que respondía a los criterios de selección de Nike en términos de estética, estilo, lealtad a la marca y capacidad de engagement (habilidad de generar atención y reacciones en las redes sociales). Asimismo, más allá de las consideraciones sobre mi cuerpo e imagen, estar vinculada a las luchas feministas fue un punto valorado por la empresa. Vera hizo referencia a este punto, al explicarme las vías que utiliza Nike para generar empatía en el público: «una es mediante las publicidades que despiertan sensibilidades, como la clásica historia emotiva, que recurre a la superación y al esfuerzo personal, y la otra es visibilizando las luchas feministas y el empoderamiento de las mujeres» (Registro de campo, 8 de noviembre de 2018).

Las campañas son finamente estudiadas, planificadas y digitadas para generar impacto y despertar emociones en la audiencia y en futuros clientes. El formato de los anuncios de NRC - Todos podemos ser corredores; Tenés un cuerpo, sos un atleta; Veni a correr con nosotras — parece estar promocionando servicios pseudo-públicos, ocultando así su rol empresarial que ha estado siempre al servicio del discurso hegemónico. Trayendo a colación la formulación de Stuart Hall (1977), esto representa 
un intento de ejercer "una autoridad social total», no solo por coerción o imposición directa de Nike de ideas dominantes, sino ganándose y configurando la aceptación de manera tal que el poder de las clases dominantes parezca legítimo y natural. Con estas decisiones comerciales, Nike pretende promocionar una «buena causa", y presentarse así como una solución, como un portador de buenas noticias y garante de felicidad. Sin embargo, eslóganes como Todos podemos ser corredores presentan la idea de que todos somos iguales y estamos en igualdad de condiciones, cuando en realidad ocultan el racismo, el clasismo, la homofobia y el sexismo, que se ponen de manifiesto en la selección de las pacers y las personalidades asociadas a la marca. El empoderamiento de las mujeres a través del deporte promocionado por campańas como el Nike Women Victory Tour no es colectivo, sino individual, ya que solo algunas serán las elegidas por la marca.

Como ya mencionamos, en la década de 1990 Nike recibió denuncias por las condiciones de trabajo en sus fábricas alrededor del mundo, que produjeron la caída de su reputación y motivaron una serie de manifestaciones en las principales ciudades de Estados Unidos, con la consecuente pérdida de acuerdos de la marca con universidades. La empresa intentó recuperar el prestigio perdido a través de la reestructuración de su modelo comercial: desde 2001 la solución fue apostar por la responsabilidad corporativa, resaltando los conceptos de deporte, medio ambiente y (más recientemente) las luchas feministas. Sus estrategias de marketing con causa hacen alarde del compromiso por la ecología (como los lanzamientos de indumentaria durante los últimos tres Mundiales), pero también del impacto comunitario. Sobre este aspecto nos referiremos en el próximo apartado.

\subsection{El impacto comunitario y La Nuestra Fútbol Feminista}

A diferencia de NRC, La Nuestra Fútbol Feminista es una organización independiente de Nike. Se trata de un colectivo formado por directoras técnicas, jugadoras y educadoras populares que desde el año 2006 entrena a mujeres y nińas en la cancha Güemes de la Villa 31 en la ciudad de Buenos Aires. Esta organización se caracteriza por no enfocarse solo en los aspectos técnicos o tácticos del fútbol, sino que encara la práctica de esta disciplina desde una perspectiva de género, reivindicando el deporte como un derecho humano, y apuesta a generar una construcción horizontal y colectiva, donde las entrenadoras y las jugadoras participen conjuntamente en la discusión de las problemáticas y la toma de decisiones. Para ello, desarrollan espacios de reflexión, talleres y festivales en los cuales las participantes comparten sus problemáticas y sus experiencias de discriminación en la actividad deportiva y en otros ámbitos de sus vidas. Además, La Nuestra busca vincularse con otras organizaciones para ampliar la reflexión en torno a sus prácticas, para fortalecer sus reclamos al Estado, y para poder financiar sus actividades, ya que se trata de 
una organización autogestiva y sin fines de lucro. Por ese motivo es que desde 2011 la asociación forma parte de la Red de Deporte para el Cambio Social, fundada por Nike junto a varias organizaciones deportivas con perspectiva de inclusión social.

Ahora bien, en 2018 Nike le propuso a las integrantes de La Nuestra firmar un convenio para estrechar su relación, en el marco de un proyecto global llamado Made to play, bajo la órbita del sector de impacto comunitario de Nike. El coordinador de este proyecto en la región es Jorge, quien vive en Brasil pero viaja asiduamente a la Argentina para monitorear su desarrollo. En una de esas visitas, pude entablar una conversación con él mientras observábamos un entrenamiento de La Nuestra (Registro de campo, 5 de diciembre de 2019). Allí me explicó que el objetivo del área de impacto comunitario es ayudar a la comunidad, fomentar los valores del deporte para desarrollar todo el potencial de las personas y que, para ello, la empresa se alía con organizaciones que fomentan el deporte en la niñez. Según Jorge, Nike hizo algunas excepciones a su política para asociarse a La Nuestra, como el hecho de trabajar con grupos segregados por género: «generalmente trabajamos con grupos mixtos, no con organizaciones de mujeres, pero sabemos que es importante que haya espacios solo para mujeres». Por otro lado, Jorge explicó que incluso el nombre del proyecto tuvo que ser modificado para adaptarlo a La Nuestra: «fue un problema, porque "Made to play" en inglés no tiene género, pero al traducirlo al español, no sabíamos cómo hacerlo. No podíamos dejarlo en inglés porque eso te distancia de la comunidad, cuando lo que quieres generar es cercanía, así que terminamos eligiendo "Hecho para jugar". Pero para La Nuestra yo no iba a aceptar que usemos "Hecho para jugar", así que lo cambiamos a "Hecha para jugar". ${ }^{13}$

No es casual que Nike incurriera en una serie de excepciones para llevar adelante la alianza con una organización con perspectiva de género como La Nuestra, en un ańo marcado por una visibilidad inusitada del movimiento feminista en la Argentina ${ }^{14}$. Para Marian, educadora popular de La Nuestra, quienes integran Nike «son muy vivos, ven que hay un nuevo interés de las mujeres por el deporte y lo explotan» (Registro de campo, 23 de julio de 2019). Las entrenadoras tienen una mirada crítica respecto de Nike y son conscientes de la motivación comercial que impulsa el accionar de la empresa, pero a pesar de estas reservas respecto de asociarse con la marca, y motivadas por la posibilidad de obtener indumentaria deportiva y

\footnotetext{
13 Ver foto 1.

14 Desde 2015, cuando tuvo lugar el primer \#NiUnaMenos en Argentina —una movilización masiva de escala nacional en contra de la violencia machista - se dio un enorme avance del movimiento de mujeres y colectivos feministas en la región, que se han estado manifestando con fuerte presencia en las calles, y que con los debates por la legalización del aborto en el Congreso Nacional durante 2018 cobraron una masividad nunca antes vista.
} 
financiación para las actividades que realizan, las integrantes de La Nuestra accedieron a firmar el convenio.

Respecto de la puesta en práctica de la alianza, al firmar el convenio las entrenadoras de La Nuestra descubrieron que no trabajarían únicamente en asociación directa con Nike, sino que la relación tendría como intermediaria a la fundación Laureus. Jorge me explicó que Laureus es un "global partner» de Nike, y es fundamental en la relación con el terreno. Nike transfiere fondos a esta fundación, que se ocupa de administrarlos y utilizarlos en beneficio de La Nuestra. Así, en el 2018 Laureus impartió talleres a las entrenadoras para ayudarlas en la organización de sus actividades, aunque estas se mostraron en desacuerdo con algunas ideas allí planteadas y molestas por la mayor carga de trabajo que implicaba la asistencia a estos talleres. Jorge admitió que «algunas cosas de los talleres no sirven para La Nuestra, pero eso está bien, la idea no es cambiar la cultura de la organización sino ayudar a organizar. Los talleres no sirvieron porque La Nuestra no es tan organizado. En los talleres les decían que dividan tareas, por ejemplo, que cada una se ocupe de una cosa. Pero acá no se organizan así, es todo más horizontal, entonces eso no es posible». En la puesta en práctica del convenio, se observa una negociación en la cual la ideología de la eficiencia empresarial entra en contradicción con las prácticas autogestivas e igualitarias que caracterizan al feminismo comunitario que promueve La Nuestra.

Otro de los pilares del convenio de Nike con La Nuestra es la plataforma Benevity, a través de la cual Nike gestiona la postulación de empleados de sus tiendas como voluntarios para distintas organizaciones de la sociedad civil aliadas a la marca. En el caso de La Nuestra, Nike nuevamente hizo una excepción, ya que las entrenadoras pidieron de forma explícita que las voluntarias fueran exclusivamente mujeres. Benevity contabiliza las horas que las empleadas trabajan como voluntarias, y Nike le paga el equivalente de esas horas trabajadas a La Nuestra, en concepto de donación, de manera que el supuesto beneficio es doble: el trabajo de las voluntarias y el ingreso de dinero. Sin embargo, Jorge lamentó que el programa de las voluntarias no funcionó tan bien en La Nuestra, y adujo su fracaso a la incompatibilidad entre el programa de voluntariado y el business de la tienda Nike, ya que las empleadas deben abandonar el local en el horario de trabajo para asistir al entrenamiento, perjudicando las ventas.

Evidentemente, la alianza de Nike con La Nuestra no está exenta de problemas. En particular, los primeros meses luego de firmar el convenio fueron especialmente conflictivos, en tanto las entrenadoras se quejaban de que la empresa había asumido algunos compromisos que no se cumplieron. Por ejemplo, se suponía que Nike iba a proveer un uniforme para cada jugadora, pero luego ese número se redujo a un pequeño porcentaje. Por otro lado, los conjuntos no tenían los colores que pedía La Nuestra, que son los que históricamente las identifican, ya que Nike utiliza 
una paleta de colores cada año y esta no se ajustaba a los requerimientos de la asociación, por lo que debieron conformarse con los tonos más parecidos que pudieron encontrar. No obstante, aquella promesa incumplida de a poco fue saldándose, de manera que en marzo de 2019 Nike realizó un evento con La Nuestra en el cual se entregaron botines a las jugadoras presentes. Luego del evento, Marian hizo el recuento de la indumentaria: "ya tienen las camisetas, los botines y el shorcito. Lo que les falta ahora es el corpiño deportivo, tienen que tomarles las medidas a todas. Es importante, porque si usan un corpiño inadecuado, pueden agarrarse mastitis» (Registro de campo, 21 de marzo de 2019). Aquí vemos nuevamente cómo las integrantes de La Nuestra justifican su alianza con Nike a partir de los efectos positivos que conlleva, en este caso para la salud de las jugadoras.

Justamente, si las entrenadoras participan de la alianza con Nike, lo hacen porque consideran que pueden obtener algo a cambio: apoyo financiero; indumentaria y elementos para el ejercicio físico que no podrían costear de otra forma; y otros beneficios inesperados como la visita de Marta Vieira Da Silva ${ }^{15}$ a un entrenamiento de La Nuestra. Además, la participación en las redes auspiciadas por Nike le ha permitido a La Nuestra conocer otras organizaciones de distintos países, lo que les ha posibilitado intercambiar experiencias e incluso crear la incipiente Red de Fútbol Feminista, donde estas agrupaciones interactúan de manera independiente a Nike. Las jugadoras de La Nuestra, por su parte, usufructúan y disfrutan de estos beneficios, aportando a cambio su presencia en los eventos auspiciados por Nike y habilitándole a la empresa el usufructo de su imagen. Esto no implica, sin embargo, que las pibas ${ }^{16}$ acepten las condiciones de esta relación sin resistencias. Esto quedó de manifiesto cuando dos voluntarias de Nike se presentaron en la cancha y juntaron a las mujeres en ronda para contarles qué ejercicios iban a hacer. En ese momento, una de las jugadoras más experimentadas las increpó: ¿Cuántos años tenés? ¿21? ¿Qué me vas a enseñar vos de fútbol a mí? Emma, entrenadora de La Nuestra, se reía al recordar esta anécdota, y agregó: «no duraron ni dos entrenamientos». Marian dijo que la solución que encontraron fue utilizarlas para entrenar a las niñas más pequeñas, "porque no sabían un pomo de fútbol, pero nos servían para llenar huecos» (Registro de campo, 23 de julio de 2019). Algunas de las jugadoras más jóvenes, por su parte, interpretaron la presencia de las voluntarias como una posibilidad para acceder a los productos de la marca a un precio accesible. Así, cuando una de las adolescentes de La Nuestra vio a las voluntarias en el entrena-

\footnotetext{
15 Marta Vieira Da Silva, más conocida como «Marta», es una delantera brasileńa distinguida como una de las mejores futbolistas de la historia que obtuvo el galardón de la FIFA a la mejor jugadora en seis oportunidades.

16 Las pibas es la categoría nativa a través de la cual se identifica a las jugadoras de La Nuestra, independientemente de su edad.
} 
miento, se acercó a ellas y les preguntó: «¿Ustedes son de Nike? ¿Me hacen descuento? Porque voy a ir a comprar algo» (Registro de campo, 15 de noviembre de 2018).

Ahora bien, tras explicar algunas de las implicancias que tiene el convenio con Nike para La Nuestra, queda pendiente responder: ¿Qué es lo que gana Nike con esta alianza? ¿Por qué elige asociarse con La Nuestra? Las propias entrenadoras plantean dudas respecto de las motivaciones de Nike para aliarse a ellas. Cuando les pregunté ¿Qué gana Nike con ustedes?, la respuesta de Marian fue inmediata: «lavan guita». Emma no parecía muy convencida: «¿Te parece? ¿Cuánto pueden lavar? ¡No nos mandaron mucha guita!» Marian insistió: «No, pero asociándose con fundaciones como Laureus tienen reducciones de impuestos». Las entrenadoras tampoco se ponían de acuerdo respecto de si los productos Nike eran objetos de consumo de las mujeres del equipo. Emma se mostraba escéptica respecto a la posibilidad de que Nike tuviera como objetivo venderles sus productos a las pibas del barrio, pero Marian planteaba que se trata de un consumo al que aspiran las jugadoras: «cuando ves la ropa que usan, los joggings, todos tienen la pipa. Si se pudieran comprar un Nike original se lo comprarían [...] Son consumidoras de sus productos. Ahora, si por ver que Nike colabora con la organización van a comprar más sus productos, eso no lo sé». Efectivamente, a partir de conversaciones que mantuve con las jugadoras de La Nuestra, pude corroborar que las pibas valoran los productos Nike, pero que están fuera de su presupuesto, por lo cual compran segundas marcas o la imitación.

La otra teoría que tenían las entrenadoras respecto de los beneficios que buscaba Nike con el convenio se relacionaban con el usufructo de las imágenes de La Nuestra: «Seguro que los videos que filman acá los usan en otros lugares, ¡si cuando vinieron a filmar hasta trajeron drones!». Emma se refería con esta alocución al evento de presentación del convenio, para el cual Nike solicitó a las integrantes de La Nuestra que firmen la cesión de imagen, autorizando a la empresa a hacer uso de las fotos y videos del evento, con el beneficio simbólico que implica para la empresa asociarse a una agrupación reconocida en el ámbito feminista.

Las escenas descritas ilustran el desequilibrio que existe en la alianza entre una organización pequeńa y autogestiva como La Nuestra y un gigante multinacional como Nike, cuyos intereses son más opacos, llevando a las elucubraciones de las entrenadoras respecto de los posibles intereses de la empresa. Sin embargo, cabe señalar que los propios empleados de Nike, que funcionan como mediadores en estas relaciones, interpretan a su manera los objetivos de la empresa para la que trabajan, y esto se expresa en los valores contrastantes que la misma pone en juego en el terreno. Así, ante la pregunta respecto de los beneficios que obtiene Nike de la alianza con La Nuestra, Jorge respondió: «Nike no hace esto por ganancia, fijate que no hay cámaras filmando el entrenamiento, en internet hay muy poca información sobre la alianza con La Nuestra». En cambio, sostiene que Nike se involucra en 
proyectos comunitarios como este como parte de una estrategia doble, que incluye por un lado alianzas como la que mantienen con La Nuestra, que tienen un alto impacto, pero a una pequeña escala, y por otro lado proyectos de menor impacto pero a escala mayor. En palabras de Jorge, «Nike sabe que no va a cambiar el mundo con proyectos como el de La Nuestra, y que no puede hacerlo solo. Por eso hace alianzas con otras organizaciones como Laureus y con gobiernos». En última instancia, Jorge justifica la presencia de la marca en la Villa 31 a partir de un estudio global encargado por Nike junto a otras organizaciones y empresas, que demuestra que las personas son mucho menos activas físicamente que antes y eso tiene muchas consecuencias negativas. Entre ellas, destaca que obtienen peores resultados educativos y menores rendimientos en el trabajo, y que las personas se enferman más y por eso se ausentan más. Jorge se mostraba genuinamente preocupado por la conclusión del estudio que planteaba que las personas podían a llegar a vivir cinco años menos debido a la inactividad física, y remarcaba que las niñas son todavía menos activas que los varones.

Ante este panorama, el rol del área de impacto comunitario de Nike consiste, según Jorge, en «influir en las personas cuando son niños, porque si lográs que se interesen por el deporte, que se diviertan, después es más probable que tengan una vida más activa». Mientras explicaba todo esto, sacó de su mochila un folleto titulado Diseñado para movimiento y me lo obsequió. Allí se encuentran resumidos los principales resultados del análisis encargado por Nike, junto con una página donde se consignan las 72 empresas, ONG, fundaciones y sectores gubernamentales que apoyan el estudio. En particular, llama la atención una página en la que se advierte que el costo de la inactividad física ascendió a más de 218000 millones de dólares en 2008 solo en seis países (Estados Unidos, Reino Unido, Rusia, China, India y Brasil) y se estima un aumento de estos costos de entre $61 \%$ y $477 \%$ para el año 2030 en cada uno de estos lugares. De manera que podemos vislumbrar cuál es el interés económico de Nike y las demás entidades que apoyan esta investigación para fomentar la actividad física en las jóvenes, y si bien puede ser cierto que la marca no obtiene un beneficio material inmediato de su asociación con La Nuestra, esta alianza se inscribe en una estrategia que busca, a mediano y largo plazo, mantener y mejorar la rentabilidad.

El hecho de que Nike es una empresa multinacional cuyo objetivo es maximizar sus ganancias y ampliar su base de consumidoras al máximo posible parece una verdad de Perogrullo. Sin embargo, es importante resaltar las formas en las que la marca adapta sus estrategias para lograr ese objetivo, considerando los contextos disímiles en los que actúa, para a su vez indagar en los efectos que esto acarrea en las subjetividades y materialidades de las personas. En este sentido, la comparación entre el modo en que Nike opera en NRC y en La Nuestra ilustra la manera 
en que la empresa interpreta la distinción por clase social. Así, NRC se encuentra bajo la órbita del sector de marketing, lo cual da cuenta de que Nike considera a las runners como consumidoras de sus productos. Por esta razón pone el foco en el aspecto comercial, creando una imagen de marca deseable para las personas de los sectores sociales más acomodados a quienes está dirigida la propuesta. Mientras que el hecho de que el convenio con La Nuestra corresponda al área de impacto comunitario implica un enfoque completamente diferente, de acuerdo con Jorge: «NRC está orientado a la clase media y está a cargo del sector de marketing. Si los de marketing se ocuparan del proyecto con La Nuestra, sería muy distinto, estarían ahora sacando fotos, usarían los slogans en inglés» ${ }^{17}$.

Justamente, en agosto de 2018, parte del staff de NRC se acercó a la Villa 31 para comenzar con el programa de fútbol femenino. La planificación desde el área de marketing quedó al desnudo: Tincho llegó a la Villa 31 con un buzo con la palabra coach estampada, un gorro y accesorios fluorescentes, un silbato para «hacer ruido» $\mathrm{y}$ arengar $^{18}$, y su smartphone listo para sacar selfies, tal como hace con quienes participan en cada sesión de NRC. Estas fotos fueron compartidas en su cuenta de Instagram: «Villa 31, hoy con La Nuestra, programa de fútbol femenino. Hermosa experiencia... emociones simples. \#HechaParaJugar \#LaNuestra \#FundacionLaureus \#Nike» ${ }^{19}$.

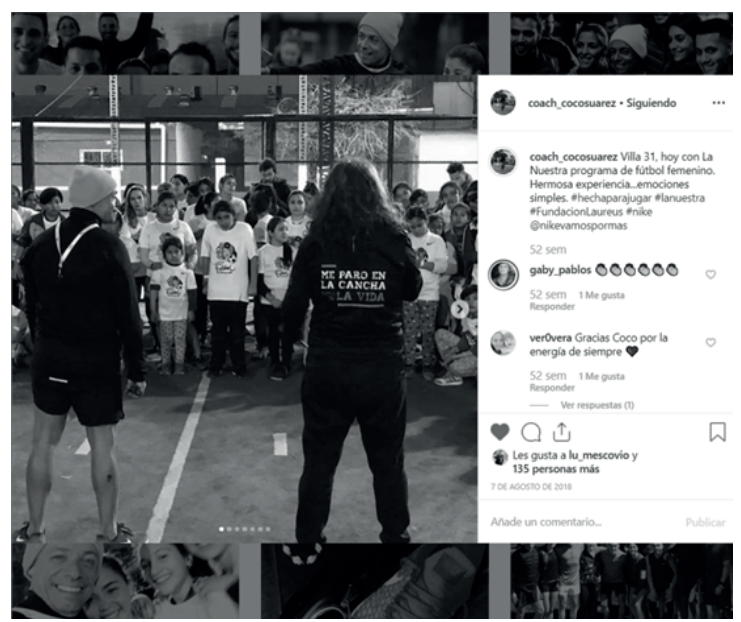

Foto 1. Publicación de Tincho, coach de NRC, en su cuenta de Instagram. Fuente: @coach_cocosuarez en Instagram.

17 La denominación de los actores, las sesiones de entrenamiento, las instrucciones y algunos conceptos generales del running en el idioma inglés es una imposición del mercado que seduce, cautiva, y plantea una nueva forma de hablar y consumir (Phillipson, 1992). Su uso es habitual y legítimo para los grupos dominantes, y por lo tanto se constituye como una práctica elitista y excluyente.

18 En términos nativos, se refiere a acompañar con exaltación y animar a quienes participan.

19 Ver en: https://bit.ly/2rlXmwk 
Como vemos, el enfoque del área de marketing se contrapone con los ideales del sector de impacto comunitario que defiende Jorge, quien sostiene que su área busca cambiar el mundo en lugar de obtener ganancias, mejorando la vida de las personas, a las que no interpreta como consumidoras. Como hemos señalado, no obstante, la oposición entre el enfoque de las áreas de marketing y de impacto comunitario no es tan tajante, ya que el objetivo de cambiar el mundo no es inocente, sino que responde a un interés económico a largo plazo y se inscribe en una estrategia que busca asociar la imagen de la empresa a la lucha feminista.

\section{Consideraciones Finales}

A lo largo de este trabajo hemos mostrado distintas maneras a través de las cuales Nike busca interpelar a las mujeres. En un contexto en el cual el feminismo ha cobrado gran relevancia a nivel nacional y regional, el discurso de la marca se ajusta para asociarse a esta "buena causa», generando sentidos contradictorios. Así, las publicidades más recientes de Nike proponen que las mujeres juntas son imparables, e invitan a romper los mandatos de género en relación al deporte. Hoy, las gigantografías de Belén Potassa, Estefanía Banini o Belén Casetta ${ }^{20}$ que empapelan la ciudad de Buenos Aires —al igual que las campañas como Antes que nadaponen en circulación y validan nuevas formas legítimas de ser mujer. Sin embargo, al mismo tiempo condensan estereotipos de belleza renovados, mostrando mujeres esbeltas pero torneadas (aunque no demasiado). Los cuerpos gordos, abyectos, disidentes, siguen ausentes en las publicidades, salvo para ser ridiculizados y presentados como indeseables, asociados a la inmovilidad que Nike pretende combatir.

Estas contradicciones también las encontramos en los proyectos que Nike mantiene en el territorio. Mientras la marca impulsa a las mujeres de su running team a desafiar viejos argumentos biologicistas que negaban su capacidad de correr largas distancias - y en el proceso, a que consuman los productos Nike y se inscriban en sus carreras aranceladas-, al mismo tiempo elige como sus referentes en el campo a aquellas mujeres que responden a los ideales hegemónicos de belleza femenina. Las estrategias en el terreno además están atravesadas por clivajes de clase, en tanto la marca adopta una posición netamente comercial en el barrio opulento de Palermo, cuyas habitantes interpreta como consumidoras, pero se presenta como ajena a todo interés monetario en su alianza con La Nuestra en la Villa 31. Aquí, el interés por fomentar la cultura física para resguardar los intereses de Nike (y otras

\footnotetext{
20 Belén Casetta es una corredora argentina especializada en carreras de 3000 metros con obstáculos, portadora de actuales récord nacional y sudamericano. Es atleta Nike y fue parte de la campańa Hacete escuchar, que buscaba inspirar a las mujeres a alzar su voz. Ver en: https://bit.ly/2SgHN3W
} 
instituciones) a futuro aparece como el principal motivador de la marca, sumado a una búsqueda oportunista de asociarse a una agrupación feminista en un contexto social propicio.

En este sentido, Nike representa al feminismo a través de imágenes que transmiten mensajes que son simultáneamente liberadores y opresivos. Las referencias al colectivo de mujeres se contraponen con reivindicaciones del esfuerzo individual que, en conjunto con la estrategia de "esponsoreo" de Nike, plantean un escenario meritocrático en el cual sus atletas se «salvan» solas, sin sus compañeras. Como señalamos, Nike pone en circulación un «feminismo estéticamente despolitizado" (Goldman, Heath y Smith, 1991), promoviendo una idea individualista de empoderamiento femenino. De este modo, la marca limpia su imagen teñida por las denuncias de trabajo infantil, el uso de talleres clandestinos y la explotación de mujeres en la fabricación de sus productos, y no pone en cuestionamiento las condiciones estructurales que sostienen la desigualdad.

Ahora bien, ¿cuáles son las consecuencias de las prácticas de Nike sobre la subjetividad y la materialidad de las mujeres? En el caso de NRC, la posibilidad de resistencia se encuentra restringida ya que allí Nike se relaciona con las deportistas en su carácter de consumidoras. En este contexto, la ideología individualista que promueve la empresa tiene mayor penetración en tanto los logros personales son recompensados con prestigio y bienes valorados en el campo. Aquellas que no se adaptan a esta lógica solo tienen como posibilidad de acción abandonar el espacio de entrenamiento. Por otro lado, si bien La Nuestra corre el riesgo de que su imagen sea utilizada por Nike para llevar a cabo fines opuestos a sus principios, sus integrantes - al estar organizadas en un colectivo feminista de forma horizontal — se encuentran en mejores condiciones para negociar y resistir la imposición de sus sentidos. Prueba de eso son las «excepciones» a sus políticas que la empresa más poderosa de la industria deportiva a nivel global debió realizar para que las futbolistas accedan a firmar un convenio. A partir de esta experiencia, nos preguntamos si, en el afán de vincularse a las luchas feministas en la actualidad, a Nike se le escapan por los intersticios una serie de imágenes, sentidos y prácticas que no responden a «lo que ellos quieren».

\section{REFERENCIAS}

Ahmed, S. (2019). La promesa de la felicidad. Una crítica cultural al imperativo de la alegría. Ciudad Autónoma de Buenos Aires: Caja Negra.

Arbio Grattone, M. (2 de septiembre de 2018). Nike busca complicidad con el feminismo. Disponible en https://feminacida.com.ar/nike-busca-complicidad-con-el-feminismo/ 
Arizaga, C. (2017). Sociología de la felicidad: autenticidad, bienestar y management del yo. Ciudad Autónoma de Buenos Aires: Biblos.

Banet-Weiser, S. (2015). Keynote Address: Media, Markets, Gender: Economies of Visibility in a Neoliberal Moment. The Communication Review, 18(1), 53-70.

Bourdieu, P. (1990). ¿Cómo se puede ser deportista? En Sociología y cultura (pp. 193-214). México: Grijalbo.

Bourdieu, P. (2012) [1979]. La Distinción. Criterio y bases sociales del gusto. Madrid: Taurus. Boyd, G. G.-D. (2016). The Girl Effect: A Neoliberal Instrumentalization of Gender Equality. Consilience: The Journal of Sustainable Development, 15(1), 146-180.

Clarín (1 de septiembre de 2018). Disponible en https://www.clarin.com/entremujeres/ publicidad-feminista-nike-viraliza-argentina-guino-favor-aborto_0_rk4OIvdwQ. html

Cooky, C., Messner, M. A. y Musto, M. (2015). «It's Dude Time!»: A Quarter Century of Excluding Women's Sports in Televised News and Highlight Shows. Communication and Sport, 3, 261-287.

Cranmer, G. A., Brann, M. y Bowman, N. D. (2014). Male athletes, female aesthetics: The continued ambivalence toward female athletes in ESPN's The Body Issue. International Journal of Sport Communication, 7(2), 145-165.

De Lauretis, T. (1989). La tecnología del género. En Technologies of Gender. Essays on Theory, Film and Fiction (pp. 1-30). Londres: Macmillan Press.

Economía Femini(s)ta (1 de septiembre de 2018). Disponible en https://economiafeminita. com/nike-y-feminismo/

Garton, G. (2017). «Fit girls». Corporalidad, identidad y género en las representaciones de mujeres futbolistas. Bajo Palabra. Revista de Filosofía, (16), 39-49.

Garton, G. e Hijós, N. (2017). La mujer deportista en las redes sociales: un análisis de los consumos deportivos y sus producciones estéticas. Revista Hipertextos. Capitalismo, Técnica y Sociedad en debate, 5(8), 83-105.

Garton, G. e Hijós, N. (2018). «La deportista moderna»: género, clase y consumo en el fútbol, running y hockey argentinos. Antipoda. Revista de Antropología y Arqueología ,(30), 23-42.

Gil, G. J. (2018). Deporte y estilos de vida. El running en Argentina. Antípoda. Revista de Antropología y Arqueología, (30), 43-63.

Goldman, R., Heath, D. y Smith, S. (1991). Commodity Feminism. Critical Studies in Mass Communication, 8(3), 333-351.

Guber, R. (2001). Etnografía. Método, campo y reflexividad. Buenos Aires: Norma.

Hall, S. (1977). Culture, the Media and the Ideological Effect. En J. Curran, M. Gurevitch y J. Woollacott (eds.), Mass Communication and Society (pp. 332-333). Londres: Edward Arnold.

Infobae (1 de septiembre de 2018). Recuperado de https://www.infobae.com/america/ america-latina/2018/09/01/nike-rompe-los-moldes-con-un-comercial-feminista-yalejado-de-los-estereotipos-de-genero/ 
Lucas, S. (2000). Nike’s Commercial Solution: Girls, Sneakers, and Salvation. International Review for the Sociology of Sport, 35(2), 149-164.

Malinowski, B. (1972) [1922]. Los argonautas del Pacífico Occidental. Estudio sobre el comercio y aventura entre los indígenas de los archipiélagos de la Nueva Guinéa melanésic. Barcelona: Altaya.

Phillipson, R. (1992). Linguistic Imperialism. Oxford: Oxford University Press.

Reichart Smith, L. y Sanderson, J. (2015). I'm Going to Instagram It! An Analysis of Athlete Self-Presentation on Instagram. Journal of Broadcasting and Electronic Media ,(59), 342-358.

Scharagrodsky, P. (2016). Mujeres en movimiento. Deporte, cultura física y feminidades. Argentina, 1870-1980. Buenos Aires: Prometeo.

Schmitt, B. H. (1999). Experiential marketing: how to get customers to sense, feel, think, act, and relate to your company and brands. Nueva York: The Free Press. 